\title{
Optimization Design and Performance Analysis of Vehicle Powertrain Mounting System
}

\author{
Han Zhou ${ }^{1}$, Hui Liu ${ }^{1,2^{*}}$, Pu Gao ${ }^{1}$ and Chang-Le Xiang ${ }^{1,2}$
}

\begin{abstract}
The design strategies for powertrain mounting systems play an important role in the reduction of vehicular vibration and noise. As stiffness and damping elements connecting the transmission system and vehicle body, the rubber mount exhibits better vibration isolation performance than the rigid connection. This paper presents a complete design process of the mounting system, including the vibration decoupling, vibration simulation analysis, topology optimization, and experimental verification. Based on the 6-degrees-of-freedom vibration coupling model of the powertrain mounting system, an optimization algorithm is used to extract the best design parameters of each mount, thus rendering the mounting system fully decoupled and the natural frequency well configured, and the optimal parameters are used to design the mounting system. Subsequently, vibration simulation analysis is applied to the mounting system, considering both transmission and road excitations. According to the results of finite element analysis, the topological structure of the metal frame of the front mount is optimized to improve the strength and dynamic characteristics of the mounting system. Finally, the vibration bench test is used to verify the availability of the optimization design with the analysis of acceleration response and vibration transmissibility of the mounting system. The results show that the vibration isolation performance of the mounting system can be improved effectively using the vibration optimal decoupling method, and the structural modification of the metal frame can well promote the dynamic characteristics of the mounting system.
\end{abstract}

Keywords: Mounting system, Optimization algorithm, Vibration simulation analysis, Topological structure, Acceleration response, Vibration transmissibility

\section{Introduction}

The vibration isolation design of vehicle powertrain systems is important for improving the noise, vibration, and harshness performance of vehicles, and it has been widely studied. The rubber mount structure design of the transmission system, which is the main vibration source, directly affects the vibration coupling state of each degree of freedom (DOF) of the powertrain system, and also affects the vehicle ride and handling performance [1]. Therefore, vibration optimal decoupling is an effective way to improve the vibration isolation effect of the rubber mount [2].

Johnson et al. [3], for the first time, performed the optimization of the mounting system design. He considered

\footnotetext{
*Correspondence: liuhui_bit@163.com

${ }^{1}$ School of Mechanical Engineering, Beijing Institute of Technology, Beijing 100081, China

Full list of author information is available at the end of the article
}

the allocation of system natural frequency and the vibration decoupling between DOFs as the objective function and the stiffness and position of mounts as design variables to perform the optimization. Consequently, vibration coupling between each translational DOF was reduced and the system natural frequencies were ensured beyond the desired range. For the vibration of the engine mounting system, Hata et al. [4] pointed out that damping effect achieved by optimizing the mount position is better than that obtained by optimizing the mount stiffness. Demic [5] considered the response force and torque of the mounting points as the objective function to optimize the positions of the mounting system. Furthermore, this method was suitable for both rubber mounts and hydraulic mounts.

Sun et al. [6] decoupled the stiffness matrix of the powertrain mounting system and achieved the vibration decoupling of the system. Hu et al. [7] proposed a
Springer Open

(c) The Author(s) 2018. This article is distributed under the terms of the Creative Commons Attribution 4.0 International License (http://creativecommons.org/licenses/by/4.0/), which permits unrestricted use, distribution, and reproduction in any medium, provided you give appropriate credit to the original author(s) and the source, provide a link to the Creative Commons license, and indicate if changes were made. 
method for investigating a powertrain system with spectrally varying mount properties, especially for torque roll axis decoupling. Refs. [8, 9] established the 12-DOF model of the mounting system using the ADAMS software, and researched its vibration isolation performance. Refs. [10-12] utilized the multi-objective topology optimization to modify the structure of the mounting system, considering the static and dynamic loads of the system. Shangguan et al. [13,14] established the 13-DOF dynamic model, which includes 6 DOFs of the powertrain, 3 DOFs of the body, and 4 DOFs of the unsprung mass. Considering the vibration and left ear noise as the objective function, parameter matching and optimization of the mounting system were carried out to achieve better vibration isolation performance. In addition, he also investigated the effect of different damage parameters on the prediction of fatigue life of rubber isolators. Angrosch et al. [15] investigated the dynamic performance of hydraulic mounting systems, considering engine torque and road excitation comprehensively. Zhen et al. [16] established 1-DOF and 3-DOF models, considering the influence of the stiffness ratio of the mount frame on the vibration isolation material. To ensure that the natural frequency of the system is lower than the first-order harmonic frequency of the engine excitation, the stiffness of the mount frame should be 1-10 times that of the vibration isolation material. Wang et al. [17] considered the generalized force transmissibility (GFT) and sum of GFT integrals as the vibration isolation index, and proposed an optimization approach for powertrain mounting systems.

In recent years, active and semi-active mounts have become a hot topic in the research on powertrain mounting systems. Fan et al. [18] analyzed the configuration of a new semi-active hydraulic mount with a variable-stiffness decoupling membrane and tested its dynamic characteristics. Chen et al. [19] researched the dynamic model and experimental testing of magnetorheological fluid mounts, especially at a wide frequency. Ladipo et al. [20] presented the simulation of magnetorheological elastomers (MREs) as engine mounts. A four-parameter model was used to model the MRE mounts and the performance was compared with those of passive or rubber mounts. Zheng et al. [21, 22] used the aforementioned model to control the engine mount system with concurrent consideration of random road input and engine excitation. Pan et al. [23] designed the fuzzy-proportional-integralderivative switching control strategy for the magnetorheological semi-active mounting system. Farjoud et al. [24] developed a detailed mathematical model of semi-active magnetorheological engine and transmission mounts using multi-physics modeling techniques for physical systems with various energy domains.
In previous studies, researchers only optimized the mounting system according to the results of the vibration decoupling, or only applied the structural topology optimization to the mount frame, and subsequently verified the validity of the design scheme via simulation or experiment. A comprehensive and complete process of optimization design and performance analysis of vehicle powertrain mounting systems has not been studied yet.

This paper presents a complete design process of the mounting system, including the vibration decoupling, vibration simulation analysis, topology optimization, and experimental verification. According to the actual state of the mounting system, the 6-DOF vibration model is established. The natural frequency and vibration mode are obtained using eigenvalue analysis. Considering the low-frequency vibration decoupling rate as the objective function, the design parameters (including mount hardness, thickness, and stiffness in all directions) that render the mounting system fully decoupled and the natural frequency well configured are extracted, and the optimal parameters are used to design the mounting system. Subsequently, the mounting system is simulated and analyzed to study the vibration response. The torsional excitation of the shafting is calculated as the transmission excitation using the equivalent model, and the road excitation is simulated using the sinusoidal scanning signal based on the data of acceleration measured by the actual vehicle. A comprehensive analysis shows that the strength and dynamic characteristics of the front mount should be improved, and hence, topology optimization is applied to the metal frame. Finally, the vibration bench test of the mounting system is carried out to extract the acceleration signals in time domain and frequency domain of the upper and lower parts of the mounts. The data is analyzed and the vibration transmissibility is calculated using the corresponding root-mean-square values of acceleration. The results showed that the design process of the mounting system could well improve the vibration isolation performance.

\section{Dynamic Model of Powertrain Mounting System}

The mounts of the integrated transmission system are divided into left, right, and front mounts (see Figure 1).

The powertrain device is regarded as a rigid body with elastic support, and a simplified model of the three-point mounting system is established as shown in Figure 2. A Cartesian coordinate system $G_{0}-x y z$ is defined as the global coordinate. $G_{0}$ is the center of mass in static balance; the $x$-axis is parallel to the output axis of the integrated transmission system; the positive $y$-axis indicates the vehicle driving direction; the $z$-axis is determined using the right hand rule. 

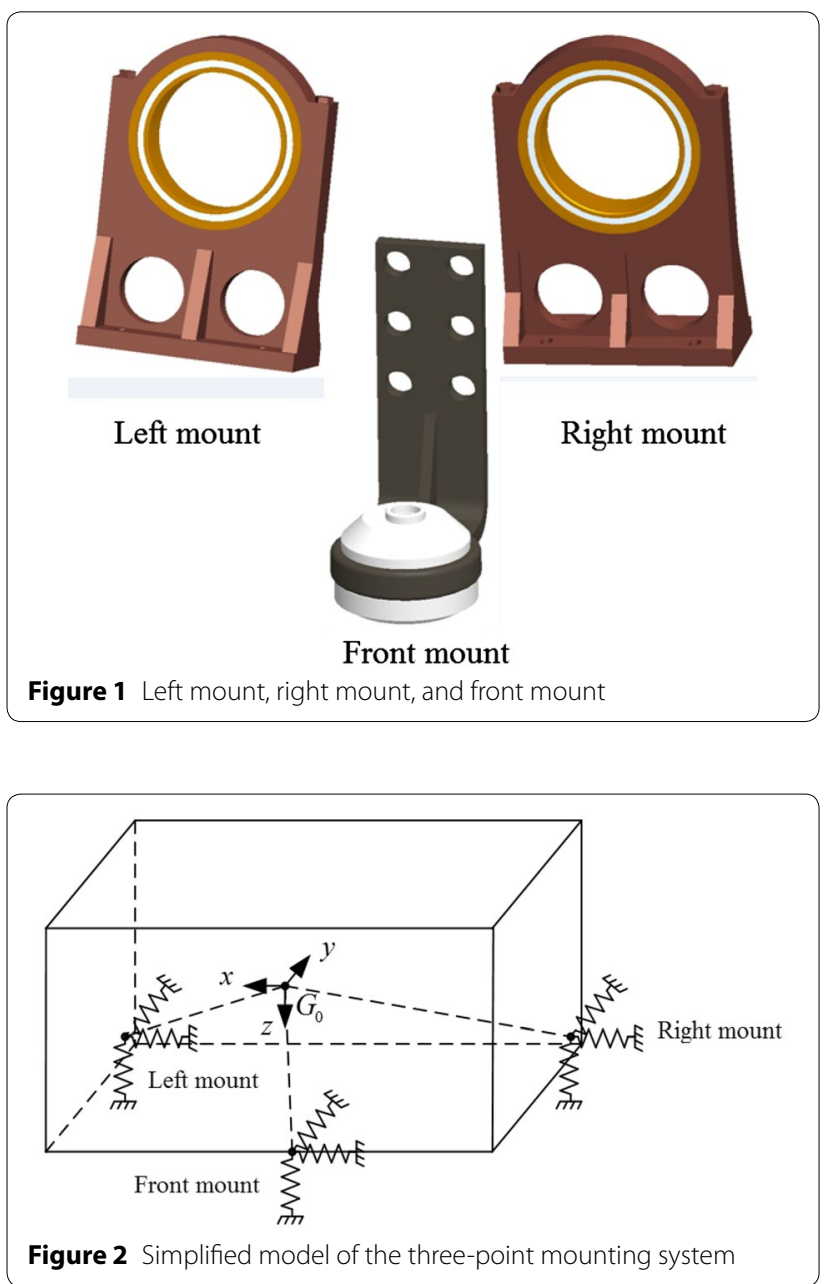

The vibration response of the system in the global coordinate system is set as $\boldsymbol{u}=\left[x, y, z, \theta_{x}, \theta_{y}, \theta_{z}\right]^{\mathrm{T}}$, where $x, y$, and $z$ are the translational motions along the three coordinate axes; $\theta_{x}, \theta_{y}$, and $\theta_{z}$ are the rotational motions around the three coordinate axes. For the powertrain mounting system simplified as a rigid body, the undamped free vibration equation in the global coordinate system is obtained as

$$
M \ddot{u}+K u=0,
$$

where

$$
\boldsymbol{M}=\left[\begin{array}{ccccc}
m & & & & \\
& m & & & \\
& & m & & \\
& & J_{x x} & -J_{x y} & -J_{x z} \\
& & -J_{x y} & J_{y y} & -J_{y z} \\
& & -J_{x z} & -J_{y z} & J_{z z}
\end{array}\right],
$$

where $m$ is the mass parameter, and $J_{x x}, J_{y y}, J_{z z}, J_{x y}, J_{x z}, J_{y x}$, and $J_{z x}$ are the inertia parameters. The 3D model of the integrated transmission system is established, the material density of the parts is set, the inertial properties are analyzed using software, and finally the system quality, position of mass center, moment of inertia, inertia product, etc. are obtained:

$$
\begin{aligned}
& \boldsymbol{K}=\sum_{i=1}^{n} \boldsymbol{E}_{i}^{\mathrm{T}} \boldsymbol{T}_{i}^{\mathrm{T}} \boldsymbol{k}_{i} \boldsymbol{T}_{i} \boldsymbol{E}_{i}, \\
& \boldsymbol{k}_{i}=\left[\begin{array}{lll}
k_{u i} & & \\
& k_{v i} & \\
& & k_{w i}
\end{array}\right], \\
& \boldsymbol{E}_{i}=\left[\begin{array}{llllll}
1 & 0 & 0 & 0 & z_{i} & -y_{i} \\
0 & 1 & 0 & -z_{i} & 0 & x_{i} \\
0 & 0 & 1 & y_{i} & -x_{i} & 0
\end{array}\right], \\
& \boldsymbol{T}_{i}=\left[\begin{array}{ccccc}
\cos \alpha_{u i} & \cos \beta_{u i} & \cos \gamma_{u i} \\
\cos \alpha_{v i} & \cos \beta_{v i} & \cos \gamma_{v i} \\
\cos \alpha_{w i} & \cos \beta_{w i} & \cos \gamma_{w i}
\end{array}\right],
\end{aligned}
$$

where $\boldsymbol{k}_{i}$ is the stiffness matrix of the mount $i$, and $k_{u i}$, $k_{v i}$ and $k_{w i}$ indicate the stiffness along the elastic axes of the mount $i$. According to the empirical formula, $\boldsymbol{E}_{i}$ is the coordinate matrix of the mount $i$ obtained from the position of each point. Further, $\boldsymbol{T}_{i}$ is the orientation angle matrix of mount $i$, and the elements in the main diagonal of the matrix are 1.

The eigenvalues and eigenvectors obtained from eigenvalue analysis are employed in the vibration decoupling as described below.

\section{Vibration Optimal Decoupling of the Mounting System}

The rigid-body vibration of the mounting system is decoupled and the comprehensive vibration isolation performance of the mounting system is improved by using the vibration energy decoupling method and nonlinear optimization method.

\subsection{Design Variables}

The vibration coupling of the mounting system is closely related to the supporting position, installation angle, and stiffness of the mounts. Owing to the limitation of the vehicle arrangement, the supporting position and installation angle of the mounting cannot be changed easily. The stiffness parameters of the mounts can be independent variables of the optimization method, mainly determined by the rubber hardness and size. To facilitate the application of the optimization results to the system design, the hardness of the left and right rubber mounts and the hardness and thickness of the front rubber mount 
are considered as design variables. Therefore, there are three design variables in the optimization model:

$$
X=\left[H_{s}^{r}, H_{f}, H_{s}^{f}\right],
$$

where $H_{s}^{r}$ is the hardness of the left and right mounts; $H_{s}^{f}$ is the hardness of the front mount; $H_{f}$ is the thickness of the front mount.

\subsection{Constraint Conditions}

\subsubsection{Configuration Range of Natural Frequency}

The natural frequency of the mounting system is guaranteed to be in a reasonable range when matching the mounting system.

The natural frequency of the direction around the $y$-axis should be less than $1 / \sqrt{2}$ of the engine idling vibration frequency, and hence, the natural frequency of the $y$-axis should be

$$
f_{\theta y} \leq \frac{n N_{\min }}{Z \cdot 60} \frac{1}{\sqrt{2}},
$$

where $n$ is the number of cylinders; $N_{\min }$ is the engine idle speed; $Z$ is the number of strokes. The engine of the vehicle is a $\mathrm{V}$ type 12-cylinder engine, and the idle speed is $800 \mathrm{r} / \mathrm{min}$. The calculated natural frequency in the torsional direction should be less than $57 \mathrm{~Hz}$.

In order to ensure the service life of the mounting system, the natural frequencies of the system are generally greater than $5 \mathrm{~Hz}$; in order to avoid the resonance of the mounting system, the general requirement of the minimum difference between the natural frequencies is approximately $1 \mathrm{~Hz}$. According to the engine speed and sensitive area for the vibration of human body, the vibration frequency ranges of each direction are given by

$$
\begin{aligned}
& 5 \mathrm{~Hz} \leq f_{x} \leq 57 \mathrm{~Hz}, 5 \mathrm{~Hz} \leq f_{y} \leq 57 \mathrm{~Hz}, \\
& 6 \mathrm{~Hz} \leq f_{z} \leq 57 \mathrm{~Hz}, \\
& 5 \mathrm{~Hz} \leq f_{\theta_{x}} \leq 57 \mathrm{~Hz}, 5 \mathrm{~Hz} \leq f_{\theta_{y}} \leq 57 \mathrm{~Hz}, \\
& 5 \mathrm{~Hz} \leq f_{\theta_{z}} \leq 57 \mathrm{~Hz} .
\end{aligned}
$$

\subsubsection{Range of Rubber Hardness and Thickness}

According to the mechanical design manual and related literature, we can determine the range and initial value of the rubber hardness. According to the vehicle arrangement space, we can determine the range and initial value of the rubber thickness of the front mount, as listed in Table 1.

\subsection{Objective Function}

According to the 6-DOF dynamic equation of the system, the natural frequencies and vibration modes can be calculated. Subsequently, the energy distribution
Table 1 Ranges and initial values of design variables

\begin{tabular}{llll}
\hline Hardness and thickness of the rubber mount & Min & Initial & Max \\
\hline$H_{s}^{r}(\mathrm{HS})$ & 10 & 50 & 80 \\
$H_{f}(\mathrm{~mm})$ & 10 & 21 & 40 \\
$H_{s}^{f}(\mathrm{HS})$ & 10 & 50 & 80 \\
\hline
\end{tabular}

of the natural vibration of the system can be calculated using the quality matrix and mode shapes, and when it is expressed in the form of a matrix, it can be defined as the energy distribution matrix.

The maximum kinetic energy of the integrated transmission system in the $n$th natural vibration is

$$
\begin{aligned}
& T_{\max }^{n}=\omega_{n}^{2}\left[\phi_{n}\right]^{\mathrm{T}}[M]\left[\phi_{n}\right] / 2, \\
& T_{\max }^{n}=\frac{\omega_{n}^{2}}{2} \sum_{l=1}^{6} \sum_{k=1}^{6} \phi_{n l} \phi_{n k} m_{k l},
\end{aligned}
$$

where $\omega_{n}$ is the $n$th natural frequency of the mounting system, $m_{k l}$ is the element in the $k$ th row and $l$ th column of the mass matrix, $\phi_{n l}$ is the $l$ th element of the mode shapes $\left[\phi_{n}\right]$, and $\phi_{n k}$ is the $k$ th element.

The energy allocated to the $k$ th generalized coordinates is obtained as

$$
T_{k}=\frac{\omega_{n}^{2}}{2} \sum_{l=1}^{6} \phi_{n l} \phi_{n k} m_{k l} .
$$

In the $n$th natural vibration, the percentage of energy allocated to the $k$ th generalized coordinates in the total energy of the system is

$$
T_{n}^{k}=\frac{T_{k}}{T_{\max }^{n}}=\frac{\sum_{l=1}^{6} \phi_{n l} \phi_{n k} m_{k l}}{\sum_{l=1}^{6} \sum_{k=1}^{6} \phi_{n l} \phi_{n k} m_{k l}} \times 100 \% .
$$

The percentage $T_{n}^{k}$ is defined as the vibration decoupling rate of the DOF $k$. If $T_{n}^{k}=100 \%$, the energy of the mounting system in the $n$th natural vibration is concentrated in the $k$ th DOF, i.e., the $k$ th DOF is completely decoupled from the other DOFs.

In summary, the objective function of the energy decoupling method can be set to

$$
C_{r}(\boldsymbol{X})=\sum_{n=1}^{6}\left|100-\max _{k}\left(T_{n}^{k}\right)\right| .
$$

\subsection{Optimization Results}

Based on the integrated analysis program of iSIGHT and MATLAB, the mounting system parameters are 
Table 2 Objective function before and after optimization

\begin{tabular}{llll}
\hline Objective function & Original & Optimized & Reduction ratio (\%) \\
\hline$C_{r}$ & 172 & 114 & 34
\end{tabular}

optimized using a nonlinear method. Finally, the objective function is convergent and evidently reduced by $34 \%$, as presented in Table 2.

Before and after optimization, the frequency configuration of the mounting system is given in Table 3.

Table 3 indicates that the frequency configuration before optimization is not reasonable because the vibration frequencies in the $\theta_{x}$ and $\theta_{y}$ directions are close to the engine idle frequency and prone to resonance. The frequencies after optimization are within the frequency range and not close to the engine idle frequency.

Before and after optimization, the vibration decoupling rate of the mounting system is presented in Table 4.

Table 4 indicates that, before optimization, the decoupling rate of the system is between $31.2 \%$ and $99 \%$; the decoupling rate in the $x, \theta_{y}$, and $\theta_{z}$ directions is relatively high, and can reach more than $85 \%$; the decoupling rate in the other directions is lower than $70 \%$. After optimization, except the decoupling rate in the $\theta_{x}$ direction, which is $61.5 \%$, the rest are more than $70 \%$. The decoupling rate of the optimized system is evidently increased, and the overall isolation performance of the mounting system is improved.

By using the above method, the optimal design parameters of the system can be obtained, and the stiffness of each mount in different directions after optimization is listed in Table 5. The hardness and thickness of the rubber mount after optimization are listed in Table 6.

\subsection{Mounting Design}

The mounting cushion adopts a combination design method of vulcanized rubber, anti-aging agent, and metal frame. The appropriate choice of vulcanized rubber, proportion of anti-aging agent, and shape and size of the metal frame can result in the hardness and thickness parameters of the rubber mount presented in Table 6 . The combination of the rubber, agent, and metal frame enables the achievement of a strong bond and facilitates deformation in the directions of stretching, compression, and shearing.

\section{Vibration Simulation Analysis of the Mounting System}

In this paper, the integrated transmission box and the mounts are analyzed separately. First, the transient dynamic response of the integrated transmission box is analyzed. Subsequently, the dynamic response force of

\begin{tabular}{|c|c|c|}
\hline Direction & Original $(\mathrm{Hz})$ & Optimized (Hz) \\
\hline$x$ & 20.70 & 5.37 \\
\hline$y$ & 9.00 & 36.11 \\
\hline$z$ & 11.19 & 19.77 \\
\hline$\theta_{x}$ & 56.91 & 24.49 \\
\hline$\theta_{y}$ & 51.77 & 31.33 \\
\hline$\theta_{z}$ & 42.56 & 28.53 \\
\hline
\end{tabular}

the front mount is extracted, and finally, the static analysis of the mounts is carried out.

\subsection{Vibration Response Analysis of Integrated Transmission Box}

In order to obtain the torsional excitation of the shafting as the boundary condition to calculate the forced vibration response of the system, the normalized equivalent model of the torsional vibration of the integrated transmission is established.

The shafting of the transmission is a continuous and complex multi-DOF quality system. The mass and elastic distributions of the system are uneven, and hence, the discrete approximation model of multi-DOF concentrated mass could be adopted. The actual system is transformed into a system with rigid bodies without elastic deformation and elastic shaft sections without the moment of inertia $[13,14]$. The sixth-gear equivalent model of transmission system is shown in Figure 3.

The engine torque model is established by considering the excitation torque of the engine gas pressure and reciprocating inertia force. Subsequently, the torque signal of the sixth-gear output shaft when the engine speed is $2200 \mathrm{r} / \mathrm{min}$ is calculated using the normalized equivalent model, as shown in Figure 4.

The vertical force of left bearing housing in one period is calculated according to the force analysis of gears and shifts. The signal can be used as the boundary condition of the mounting system to calculate the forced vibration response of the system. The deformation and stress nephograms of the box calculated using finite element analysis are shown in Figure 5.

Subsequently, the reaction force at six fixed bolt holes of the front mount is extracted, as shown in Figure 6.

\subsection{Vibration Response Analysis of the Mounts 4.2.1 Response Analysis of the Transmission Excitation}

The root-mean-square values of the reaction forces at six bolt holes extracted as described above are applied to the corresponding six bolt holes in the front mount. The 
Table 4 Vibration decoupling rate of the system before and after optimization

\begin{tabular}{lll}
\hline Direction & Original (\%) & Optimized (\%) \\
\hline$x$ & 98.69 & 99.93 \\
$y$ & 31.22 & 71.41 \\
$z$ & 53.65 & 72.25 \\
$\theta_{x}$ & 65.42 & 61.50 \\
$\theta_{y}$ & 92.67 & 89.35 \\
$\theta_{z}$ & 86.65 & 90.99 \\
\hline
\end{tabular}

Table 5 Stiffness in different directions after optimization

\begin{tabular}{llll}
\hline Stiffness & Right mount (N/m) & Left mount (N/m) & $\begin{array}{l}\text { Front mount } \\
(\mathbf{N} / \mathbf{m})\end{array}$ \\
\hline$k_{x}$ & 867,805 & 867,805 & 196,711 \\
$k_{y}$ & $18,372,000$ & $18,372,000$ & 196,711 \\
$k_{z}$ & $18,372,000$ & $18,372,000$ & $21,699,000$ \\
\hline
\end{tabular}

Table 6 Hardness and thickness of the rubber mount after optimization

\begin{tabular}{ll}
\hline Hardness and thickness of the rubber mount & Optimized \\
\hline$H_{s}^{r}(\mathrm{HS})$ & 23 \\
$H_{f}(\mathrm{~mm})$ & 13 \\
$H_{s}^{f}(\mathrm{HS})$ & 79 \\
\hline
\end{tabular}

vertical force at the upper bearing is extracted, and the root-mean-square value is calculated to be loaded on the left and right mounts in the form of uniform pressure.

The deformation and stress nephograms of the mounts under the transmission excitation are shown in Figure 7.

\subsubsection{Response Analysis of the Road Excitation}

Road excitation is a significant excitation for driving a vehicle. Normally, road excitation is expressed using road surface roughness, and when loaded into the mounting model, the spatial signal must be transformed into time domain. In practical applications, we usually use the harmonic superposition method to simulate the road roughness model $[15,16]$. However, this method is too complex and difficult for the simulation of the actual situation of the road, and hence, we use the method of harmonic response analysis to analyze the vibration characteristics of each mount [12]. The maximum amplitude of vibration acceleration collected in the actual vehicle is considered as the amplitude of the input signal, and the sinusoidal scan is carried out in the range of $0.5-10 \mathrm{~Hz}$ for each mount at an interval of $0.01 \mathrm{~Hz}$.
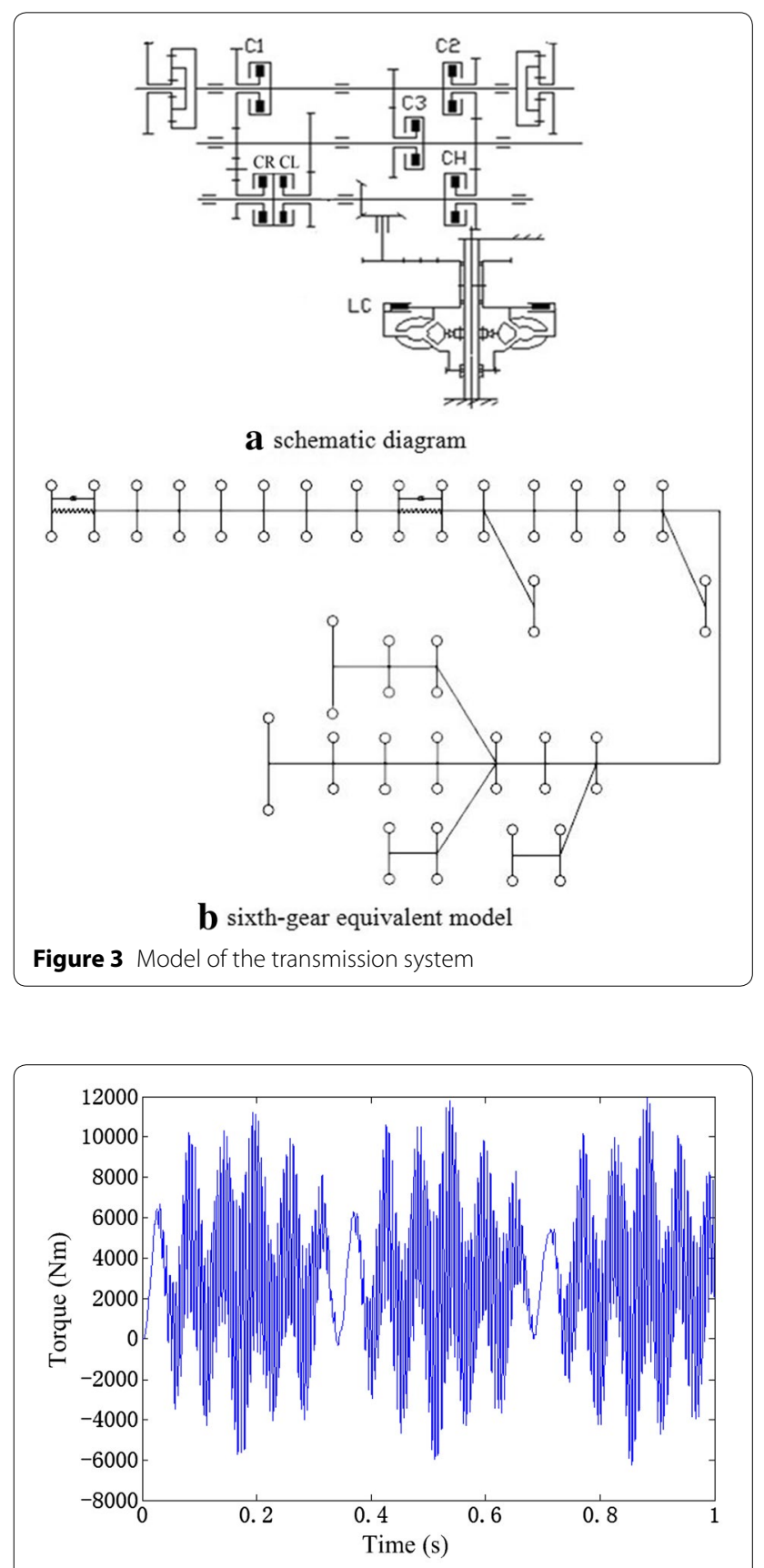

Figure 4 Torque signal of the sixth-gear output shaft

The deformation and stress nephograms of the mounts under the road excitation are shown in Figure 8.

The maximum deformation and stress of the mounts under the transmission excitation and road excitation are given in Table 7.

It can be observed from Figure 8 and Table 7 that the front part of the front mount frame has a maximum deformation of $0.82 \mathrm{~mm}$, mainly because there are no rubber blocks. The stress in the front mount is mainly 

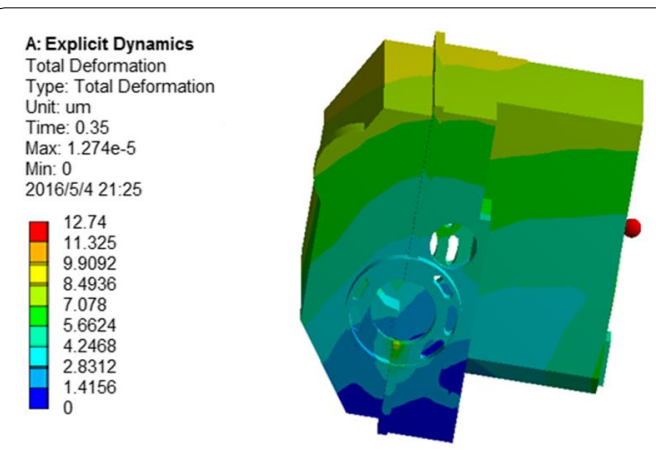

a deformation nephogram

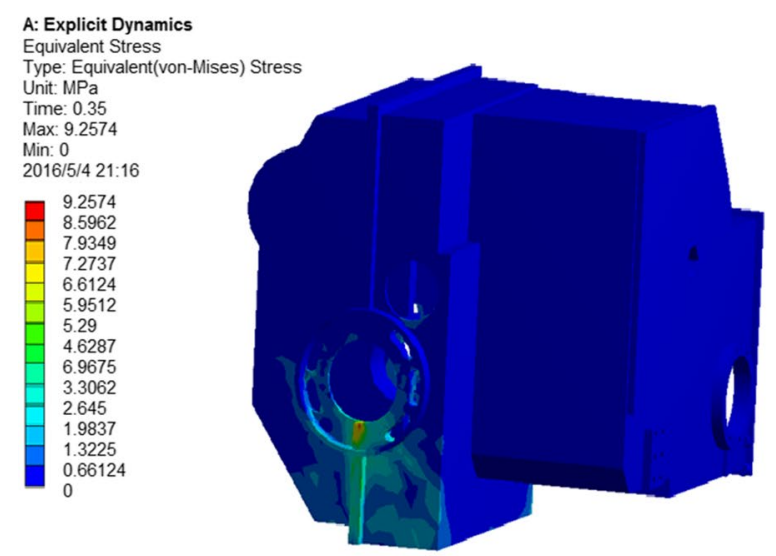

b stress nephogram

Figure 5 Deformation and stress nephograms of the box

distributed in the six bolt holes and two sides of the vertical part of the metal frame, and the bolt hole of the horizontal part has a maximum stress of $82.017 \mathrm{MPa}$. Compared with the left and right mounts, the front mount has larger deformation and stress, and is more easily damaged during use, and hence, it is necessary to improve the reliability of the front mount.

\section{Optimization Design of the Metal Frame}

We only modify the metal frame of the front mount as the left and right mounts satisfy the structural strength and performance requirements. Considering the flexibility (static) and vibration natural frequency (dynamic) of the components as the objective function, the topological structure of the metal frame of the front mount is optimized.

In this paper, a multi-objective optimization model of stiffness and low-order natural frequencies is established. The objective function is a combined index of the global response of the structure, including the weighted flexibility and weighted natural frequency. The static multi-load condition and dynamic vibration characteristics of the mounting system are considered, and the expression is given by

$$
\begin{aligned}
\min \xi(\rho)= & \sum_{k=1}^{m} w_{k}\left[\frac{C_{k}(\rho)-C_{k}^{\min }}{C_{k}^{\max }-C_{k}^{\min }}\right]^{2} \\
& +\sum_{i=1}^{n} w_{i}\left[\frac{\Lambda_{i}^{\max }-\Lambda(\rho)}{\Lambda_{i}^{\max }-\Lambda_{i}^{\min }}\right]^{\frac{1}{2}},
\end{aligned}
$$

where $C_{k}^{\max }$ and $C_{k}^{\min }$ are the maximum and minimum values of flexibility in the three working conditions, respectively, which can be obtained from the topology optimization by considering the minimum flexibility as the objective function; $\Lambda_{i}^{\max }$ and $\Lambda_{i}^{\min }$ are the maximum and minimum values of natural frequency of each order, respectively, which can be obtained from the topology optimization by considering the maximum natural frequency as the objective function; $w_{k}$ and $w_{i}$ are the weighting factors of flexibility and modal frequency, respectively.

The corresponding data is provided as input to Hyperworks and the Optistruct module is used for topology optimization. Finally, we obtain the optimized metal frame of the front mount, as shown in Figure 9.

The mass after optimization is $1.31 \mathrm{~kg}$ less than that of the original model, accounting for $14.2 \%$ of the original mass. Subsequently, analysis of the optimized metal frame shows that the maximum stress of the three working conditions [static, undulating road $(40 \mathrm{~km} / \mathrm{h})$, and cement road $(50 \mathrm{~km} / \mathrm{h})]$ is reduced to a certain extent, and the strength of the structure is enhanced. The firstorder natural frequency is $538 \mathrm{~Hz}$, which is away from the resonant sensitive region of the integrated transmission. In summary, the dynamic characteristics of the mounting system are improved.

\section{Vibration Bench Test}

The vibration acceleration signal of the upper and lower parts of each mount in time domain and frequency domain are extracted. The schematic diagram of the vibration table test is shown in Figure 10.

\subsection{Analysis of Test Results}

The gearbox remains in the sixth gear, and the engine speed is $2200 \mathrm{r} / \mathrm{min}$. From the test results, we can observe that the vibration acceleration of the upper and lower parts of each mount is reduced to a certain extent, and the attenuation effect of the lower part of the front mount is more evident than that of the others, as shown in Figure 11. 


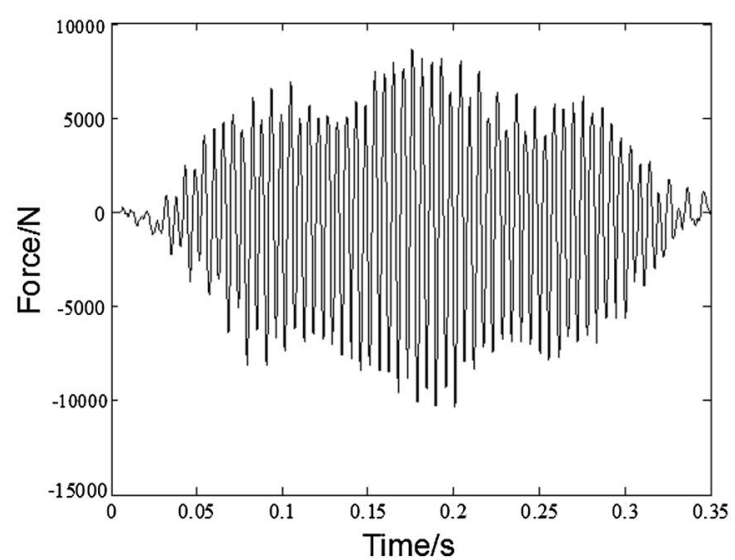

a the reaction force at upper left bolt hole

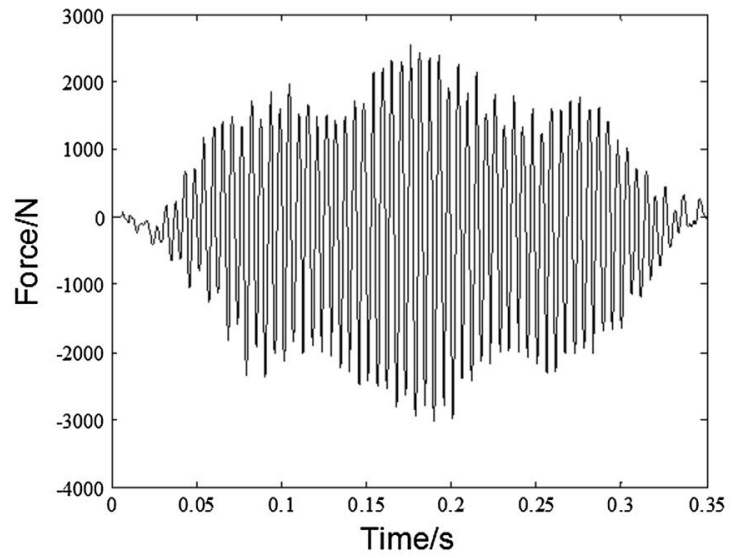

c the reaction force at middle left bolt hole

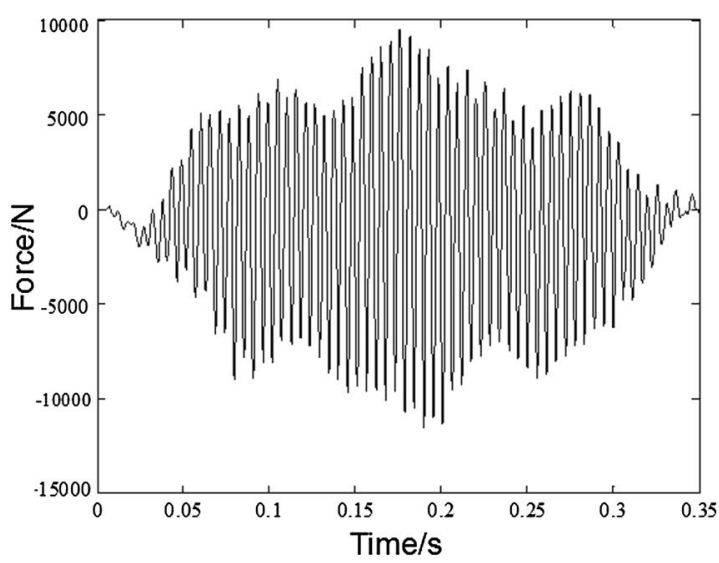

e the reaction force at lower left bolt hole

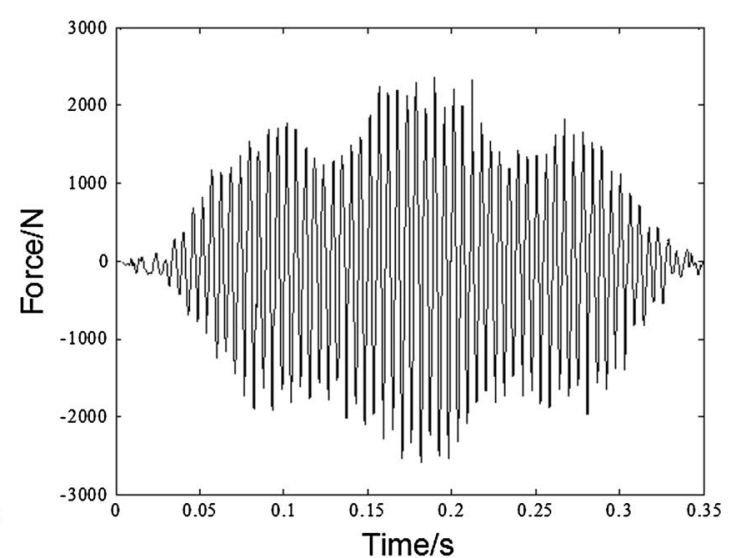

b the reaction force at upper right bolt hole

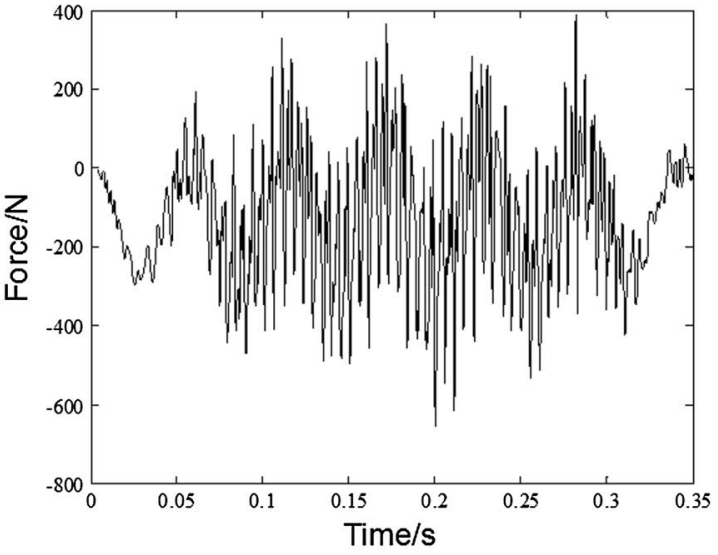

d the reaction force at middle right bolt hole

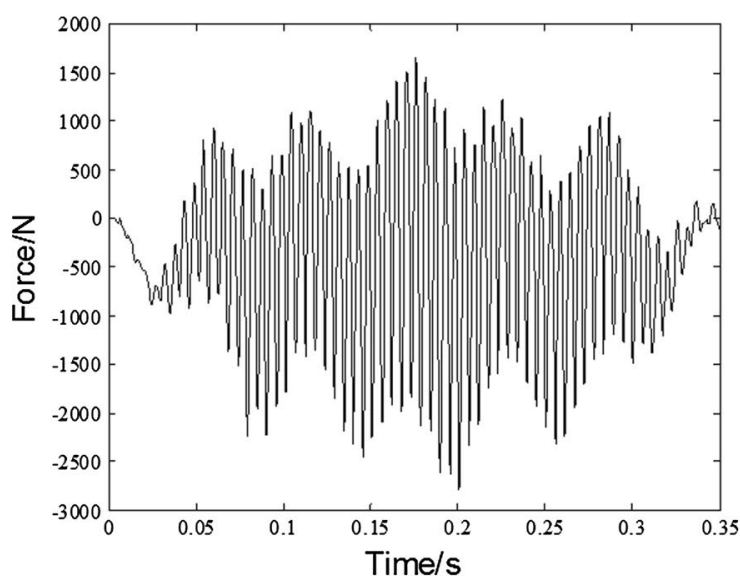

f the reaction force at lower right bolt hole

Figure 6 Reaction force at six fixed bolt holes 


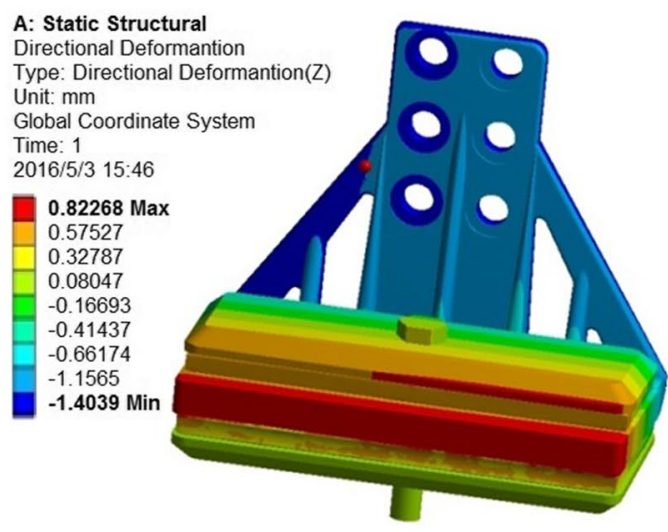

a deformation nephogram of the front mount

\section{A: Static Structural \\ Directional Deformantion \\ Type: Directional Deformantion(Z) \\ Unit: um \\ Global Coordinate System \\ Time: 1 \\ 2016/5/8 17:04

\begin{tabular}{|l}
1.6203 Max \\
1.3691 \\
1.118 \\
0.86683 \\
0.61567 \\
0.36452 \\
0.11377 \\
-0.1378 \\
-0.38893 \\
-0.64008 Min
\end{tabular}

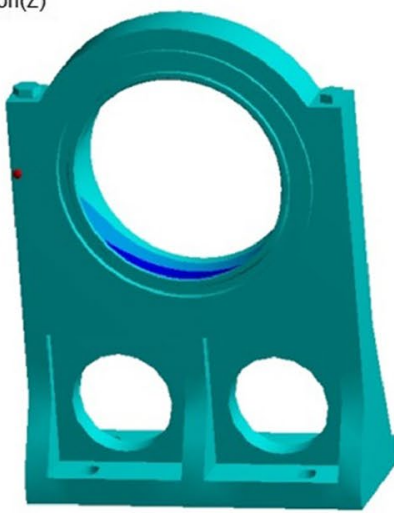

c deformation nephogram of the left mount

A: Static Structural

Directional Deformantion

Type: Directional Deformantion(Z)

Unit: um

Global Coordinate System

Time: 1

2016/5/8 17:21

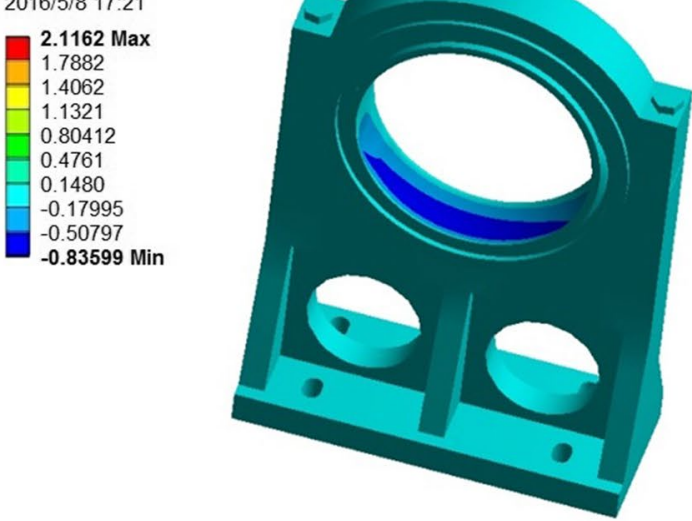

e deformation nephogram of the right mount

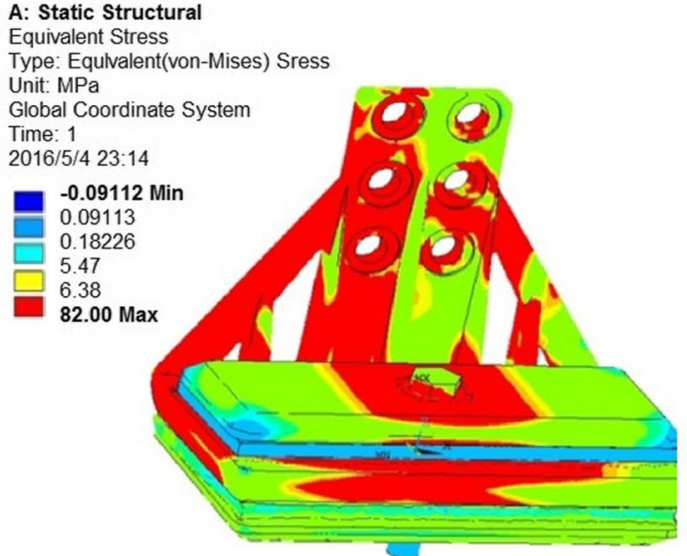

b stress nephogram of the front mount

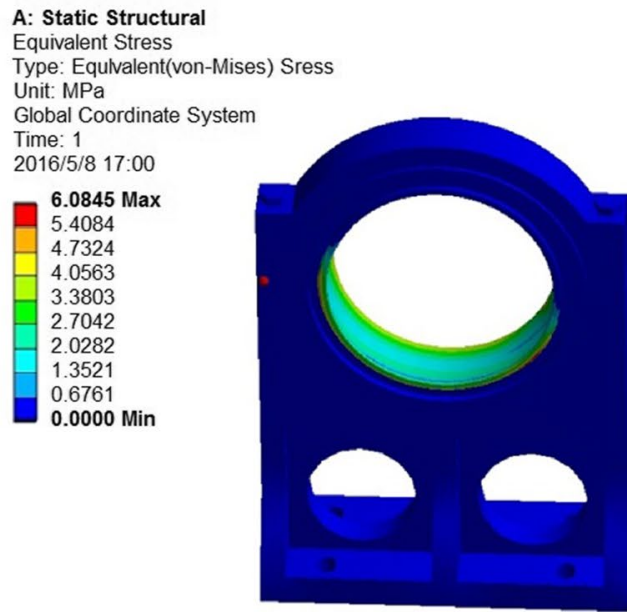

d stress nephogram of the left mount

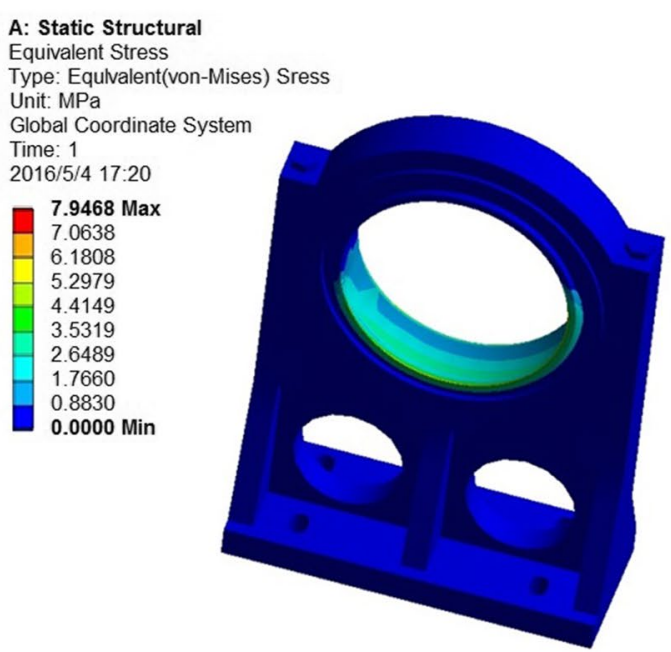

f stress nephogram of the right mount

Figure 7 Deformation and stress nephograms of the mounts under the transmission excitation 


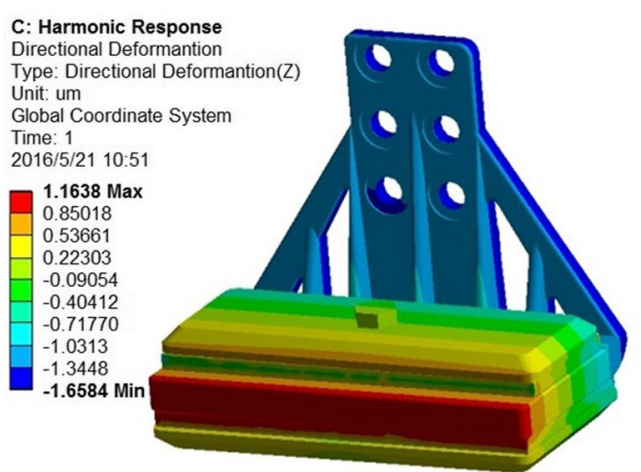

a deformation nephogram of the front mount

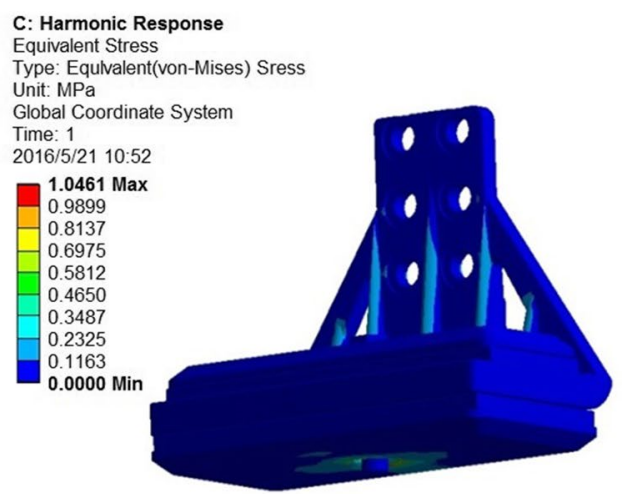

b stress nephogram of the front mount

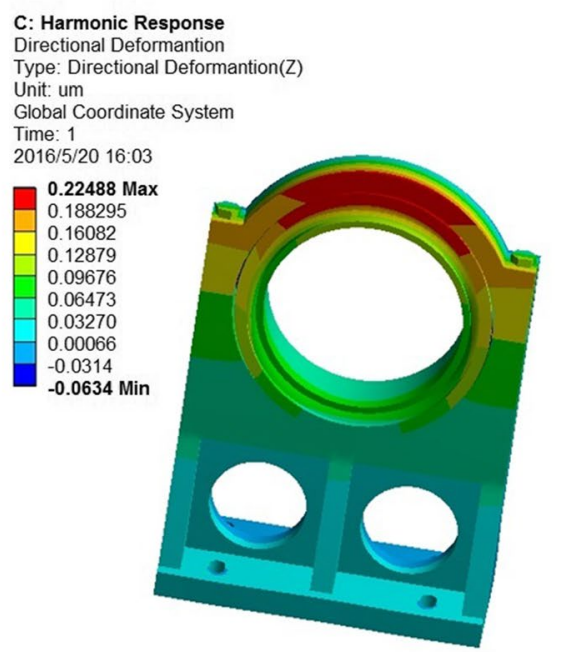

c deformation nephogram of the left and right mounts

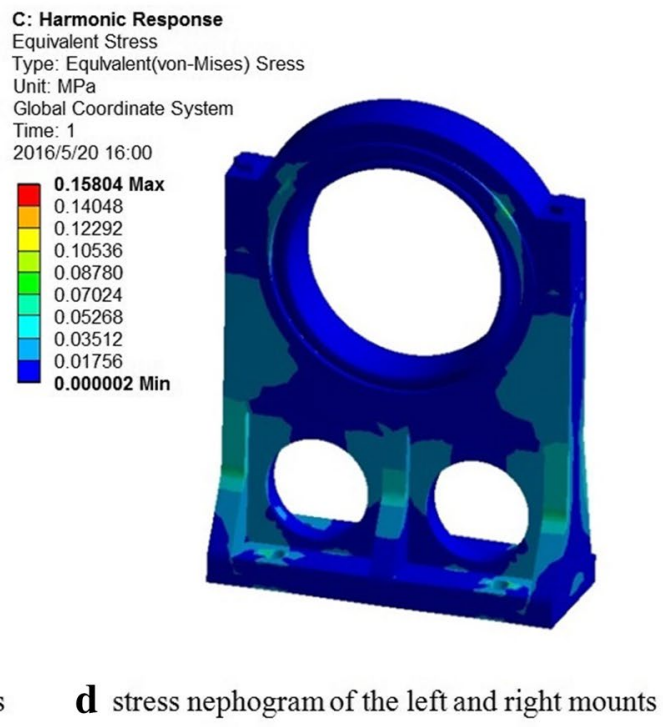

Figure 8 Deformation and stress nephograms of the mounts under the road excitation

Table 7 Maximum deformation and stress of the mounts

\begin{tabular}{lll}
\hline & Maximum deformation $(\mathbf{m m})$ & Maximum stress (MPa) \\
\hline Front mount & 0.82 & 82.017 \\
Left mount & 0.00162 & 6.08 \\
Right mount & 0.00212 & 7.94 \\
\hline
\end{tabular}

It can be observed from Figure 11 that the root-meansquare values of the vibration acceleration before and after the optimization are $4.84 g$ and $0.82 g$, respectively, indicating a reduction of $83 \%$ and hence, the vibration is evidently attenuated. This is because we optimize both the rubber and metal frame of the front mount, which changes the ratio of stiffness of the metal frame to that of the rubber. The figure of frequency domain also shows that the vibration optimal decoupling and topology optimization can evidently attenuate the vibration of the front mount, especially in the frequency band of $1250 \mathrm{~Hz}$.

Subsequently, the vibration acceleration signal of the upper and lower parts of each mount is extracted when the gearbox is in different gears, and the engine speed remains $2200 \mathrm{r} / \mathrm{min}$. The root-mean-square values of the acceleration and vibration transmissibility are calculated. The vibration transmissibility of the front mount before and after the optimization is shown in Figure 12.

Figure 12 shows that the vibration transmissibility of the front mount does not fluctuate when the gearbox is in different gears, which indicates that the vibration isolation performance of the mount is not related to the transmission ratio. The vibration transmissibility after 


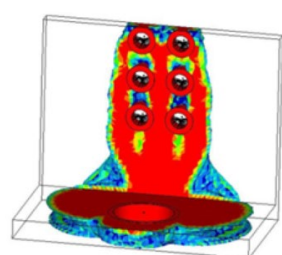

a density contours of topology optimization

Figure 9 Topology optimization of the metal frame

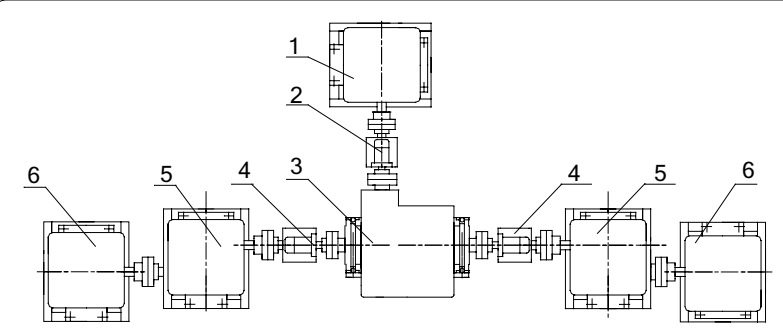

Figure 10 Schematic diagram of vibration table test. 1. Engine, 2. Input torque and speed sensors, 3. Powertrain system, 4. Output torque and speed sensors, 5. Gearbox, 6. Motor

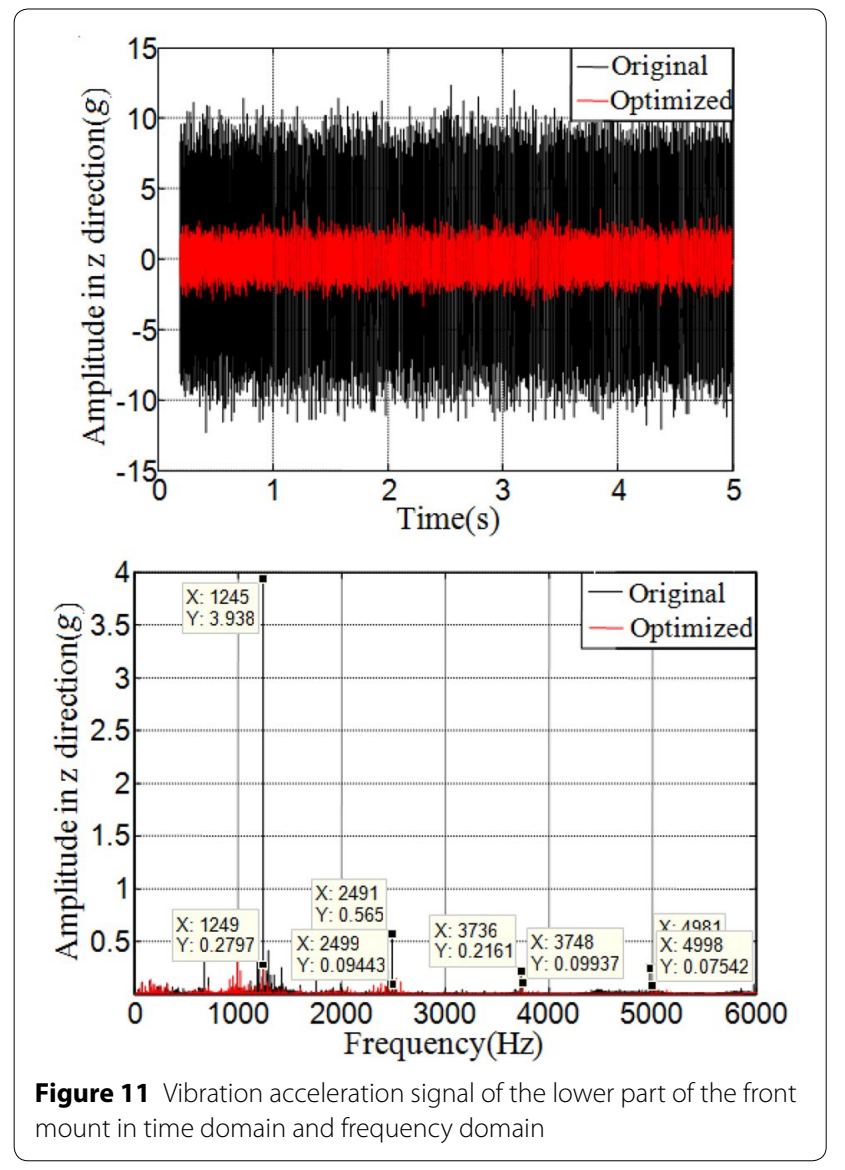

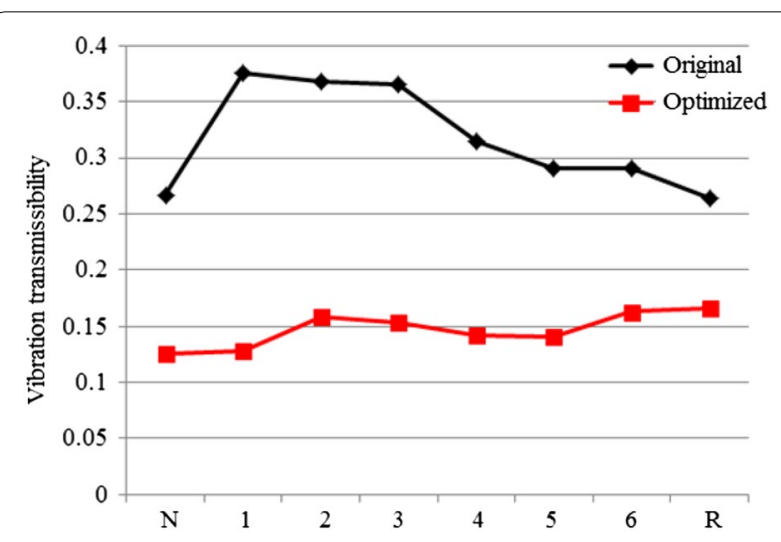

Figure 12 Vibration transmissibility of the front mount before and after the optimization

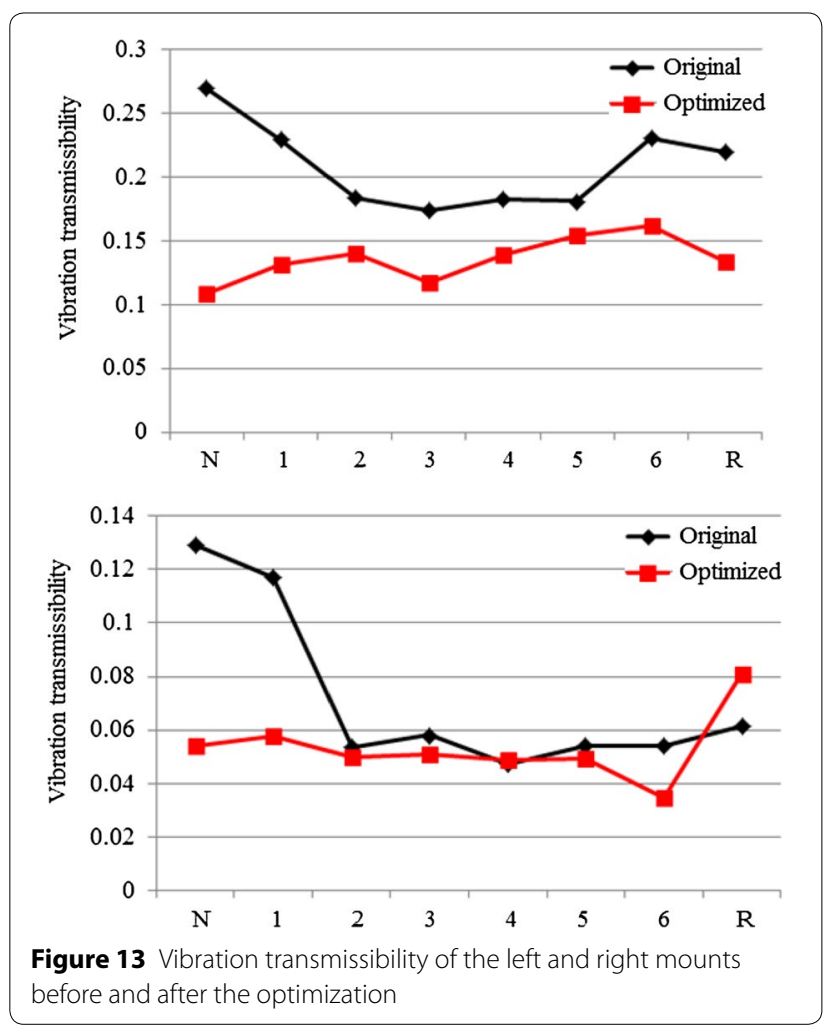

the optimization is approximately $1 / 3$ of that before the optimization. It shows that the optimization method can significantly reduce the vibration transmissibility and effectively improve the vibration isolation performance of the mounting system.

The vibration transmissibility of the left and right mounts before and after the optimization is shown in Figure 13.

From Figure 13, it can be observed that the vibration transmissibility of the left mount after the optimization 
decreases slightly and that of the right mount before and after the optimization is not significantly changed. The vibration isolation performance is not significantly improved because only the parameters of the rubber are optimized, whereas the other parts remain unchanged.

In summary, the mounting system has an apparent attenuation effect on the vibration generated by the transmission system. The vibration optimal decoupling and topology optimization have significantly improved the vibration isolation performance of the front mount and proved the effectiveness of the design scheme.

\section{Conclusions}

In this study, based on the 6-DOF coupling vibration model of the mounting system, an optimization algorithm was used to extract the best design parameters of the mounts, thus rendering the mounting system fully decoupled and frequency well configured, and the optimal parameters were used to design the mounting system. Subsequently, the vibration response of the mounting system was simulated and analyzed, considering the influence of transmission excitation and road excitation. The analysis showed that the strength and dynamic characteristics of the front mount were to be improved, and the topological structure of the metal frame was optimized. Finally, the vibration bench test was used to verify the availability of vibration decoupling and structural topology optimization, with the analysis of acceleration signal and vibration transmissibility of the mounting system.

This paper presented a complete optimization design process of the mounting system, including the vibration decoupling, vibration simulation analysis, topology optimization design, and experimental verification, and the process is instructive for the actual engineering design of mounting systems.

\section{Authors' Contributions}

$\mathrm{HL}$ was in charge of the whole trial; $\mathrm{HZ}$ wrote the manuscript; PG and C-LX assisted with sampling and laboratory analyses. All authors have read and approved the final manuscript.

\section{Author details}

${ }^{1}$ School of Mechanical Engineering, Beijing Institute of Technology, Beijing 100081, China. ${ }^{2}$ National Key Lab of Vehicular Transmission, Beijing Institute of Technology, Beijing 100081, China.

\section{Authors' Information}

Han Zhou, born in 1995, is currently a master candidate at School of Mechanical Engineering, Beijing Institute of Technology, China. His research interests include vibration reduction technology of vehicle transmission system. E-mail: vincezhou@126.com.

Hui Liu, born in 1975, is currently a professor at Beijing Institute of Technology, China. She received her PhD degree from Beijing Institute of Technology, China, in 2003. Her research interests include vehicle dynamics and electromechanical drives. E-mail: liuhui_bit@163.com.

Pu Gao, born in 1989, is currently a PhD candidate at School of Mechanical Engineering, Beijing Institute of Technology, China. He received his master degree from Yanshan University, China, in 2015. His research interests include vibration reduction technology of vehicle transmission system. E-mail: gaopu1989@126. com.

Chang-Le Xiang, born in 1963, is currently a professor at Beijing Institute of Technology, China. He received his PhD degree from Beijing Institute of Technology, China, in 2001. His research interests include vehicle dynamics and electromechanical drives. E-mail: xiangcl@bit.edu.cn.

\section{Competing Interests}

The authors declare that they have no competing interests.

\section{Ethics Approval and Consent to Participate}

Not applicable.

\section{Funding}

Supported by National Natural Science Foundation of China (Grant Nos. 51375047, 51775040).

\section{Publisher's Note}

Springer Nature remains neutral with regard to jurisdictional claims in published maps and institutional affiliations.

Received: 23 June 2017 Accepted: 16 April 2018

Published online: 26 April 2018

\section{References}

[1] XY Pan. An investigation on calculation and modeling methods for dynamic properties of a rubber isolator. Hangzhou: Zhejiang University of Technology, China, 2009. (in Chinese)

[2] Z H Lv, R L Fan. Design method for vibration uncoupling of powerplant mounting system. Chinese Journal of Mechanical Engineering, 2005, 41 (4): 49-54. (in Chinese)

[3] SR Johnson, JW Subhedar. Computer optimization of engine mounting systems. No. 790974. SAE Technical Paper, 1979.

[4] H Hata, H Tanaka. Experimental method to derive optimum engine mount system for idle shake. No. 870961. SAE Technical Paper, 1987.

[5] M Demic. A contribution to the optimization of the position and the characteristics of passenger car powertrain mounts. International Journal of Vehicle Design, 1990, 11(1): 87-103.

[6] B B Sun, Q J Zhang, Q H Sun, et al. Study on decoupled engine mounting system. Journal of Vibration Engineering, 1994, (03): 240-245. (in Chinese)

[7] X Z Li, K Chen. ADAMS based research on vibration isolation performance of powertrain mounting system. Proceedings of 2015 International Industrial Informatics and Computer Engineering Conference (IIICEC 2015), 2015: 4.

[8] J F Hu, WW Chen, H Huang. Decoupling analysis for a powertrain mounting system with acombination of hydraulic mounts. Chinese Journal of Mechanical Engineering, 2013, 26(4): 737-745.

[9] KChen, P Lv. Simulation method for vibration isolation performance of vehicle powertrain mounting system. China Mechanical Engineering, 2014, 25(20): 2830-2834. (in Chinese)

[10] Q H Zhao, X K Chen, L Wang, et al. Simulation and experimental validation of powertrain mounting bracket design obtained from multi-objective topology optimization. Advances in Mechanical Engineering, 2015, 7(6): 1687814015591317.

[11] J F Zhu, Y Lin, G B Shi, et al. Topology optimization of engine mount bracket with consideration of engineering constraints. Automotive Engineering. 2014(12): 1508-1512. (in Chinese)

[12] L C Zhang, Q H Zhao, HX Zhang, et al. Multi-objective topology optimization for the mount bracket of vehicle powertrain. Automotive Engineering, 2017, 5: 551-555. (in Chinese)

[13] W B Shangguan, X A Liu, Z P LV, et al. Design method of automotive powertrain mounting system based on vibration and noise limitations of vehicle level. Mechanical Systems and Signal Processing, 2016, 76: 677-695.

[14] W B Shangguan, X C Duan, Q K Liu, et al. Study on the effect of different damage parameters on the predicting fatigue life of rubber isolators. Journal of Mechanical Engineering, 2016, 52(2): 116-126. (in Chinese)

[15] B Angrosch, M Plöchl, W Reinalter. Mode decoupling concepts of an engine mount system for practical application. Proceedings of the 
Institution of Mechanical Engineers, Part K: Journal of Multi-body Dynamics, 2015, 229(4): 331-343.

[16] J Zhen, S Fredrickson. The effect of mounting structure stiffness on mounting system isolation performance on off-highway machines. No. 2015-01-2350. SAE Technical Paper, 2015.

[17] Y N Wang, Z H Lv. Optimal design method of power-train mounting system for generalized force transmissibility reduction. Journal of Mechanical Engineering, 2011, 50(11): 52-58. (in Chinese)

[18] R L Fan, X L Zhang. Study on semi-active hydraulic mount with variablestiffness decoupling membrane. Journal of Mechanical Engineering, 2015, 51(14): 108-114. (in Chinese)

[19] S W Chen, P F Du, R Li, et al. Dynamic parametric modeling and identification of magnetorheological fluid engine mounts. Journal of Mechanical Engineering, 2016, 52(8): 29-35. (in Chinese)

[20] I L Ladipo, J D Fadly, W F Faris. Characterization of magnetorheological elastomer (MRE) engine mounts. Materials Today: Proceedings, 2016, 3(2): 411-418.

[21] L Zheng, ZX Deng, J Pang, et al. Semi-active vibration control of a vehicle featuring magneto-rheological engine mount. Automotive Engineering, 2016, 2: 221-228. (in Chinese)

[22] L Zheng, Q B Liu, Z L You, et al. Development of modified lumped parameter model involving amplitude-dependence characteristics on semiactive engine mount and experimental verification. Journal of Mechanical Engineering, 2017, 53(14): 98-105. (in Chinese)
[23] D Y Pan, Z Tang, P C Shi, et al. Applying fuzzy-PID switching control to magnetorheological semi-active suspension system. Mechanical Science and Technology for Aerospace Engineering. 2017, 2: 292-297. (in Chinese)

[24] A Farjoud, RTaylor, E Schumann, et al. Advanced semi-active engine and transmission mounts: tools for modelling, analysis, design, and tuning. Vehicle System Dynamics, 2014, 52(2): 218-243.

[25] C L Fang, Z D Feng, Z H Lv. An investigation into the natural characteristics and structural modification control of torsional vibration of automotive power train system. Automotive Engineering, 1993, 15(1): 9-18. (in (hinese)

[26] P Schwibinger, D Hendrick, WWu, et al. Reduction of vibration and noise in the powertrain of passenger cars with elastomer dampers. No. 910616. SAE Technical Paper, 1991.

[27] Z Zhou. Study on virtual test method based on real road spectrum for virtual fatigue prediction. Hunan University, 2013. (in Chinese)

[28] X F Han. Several researches of vehicle NVH test methods. Hefei University of Technology, 2008. (in Chinese)

\section{Submit your manuscript to a SpringerOpen ${ }^{\circ}$ journal and benefit from:}

- Convenient online submission

- Rigorous peer review

- Open access: articles freely available online

- High visibility within the field

- Retaining the copyright to your article

Submit your next manuscript at $\boldsymbol{\nabla}$ springeropen.com 